Original article

Reprint

\title{
Medicamentous therapy of stable coronary artery disease sensu the guidelines on myocardial revascularization
}

\author{
Olga M. Posnenkova ${ }^{1}$, Ekaterina N. Genkal ${ }^{2}$, Yulia V. Popova ${ }^{1}$, \\ Anton R. Kiselev ${ }^{1}$, Vladimir I. Gridnev ${ }^{1}$ \\ ${ }^{1}$ Saratov State Medical University, Saratov, Russia \\ ${ }^{2}$ Independent scientist
}

Received 15 July 2019, Accepted 20 November 2020

Original Text (c) Posnenkova O.M., Genkal E.N., Popova Yu.V., Kiselev A.R., Gridnev V.I., 2019, published in Saratov Journal of Medical Scientific Research 2019; 15 (3): 812-817.

(C) 2020, Posnenkova O.M., Genkal E.N., Popova Yu.V., Kiselev A.R., Gridnev V.I.

(C) 2020, Saratov Medical Journal

\begin{abstract}
:
Objective: based on the Russian Federation multicenter registry data, to assess the comprehensiveness of medicamentous therapy in patients with stable coronary artery disease (CAD) from the perspective of 2018 European Society of Cardiology (ESC-2018) recommendations for myocardial revascularization and 2017 American Appropriate Use Criteria (AUC-2017) for the expediency of revascularization.

Materials and methods. Anamnestic data of 1531 patients with stable CAD (average age: $61.7 \pm 9.8$ years; $76 \%$ men) were studied. The data source was the Russian Federation multicenter registry of patients with arterial hypertension, CAD, and chronic heart failure. We identified the prescription of optimal medical therapy (OMT) sensu ESC-2018, maximal anti-ischemic therapy (MAT) sensu AUC-2017, and compliance of drug therapy with ESC-2018 and AUC-2017 simultaneously. OMT included at least one anti-ischemic medication + antiplatelet agent + statin + short-acting nitrate + blocker of the renin-angiotensin system in the presence of hypertension, diabetes mellitus, or heart failure. MAT included at least two anti-ischemic pharmaceutical drugs. Compliance with these criteria was determined in the groups of patients who underwent, or did not undergo, myocardial revascularization, as well as among those, for whom invasive treatment was indicated as the first priority, as the second priority, or was not indicated at all, according to ESC-2018 and AUC-2017.

Results. Among patients who received solely medicamentous therapy $(n=924)$, OMT was prescribed in $18 \%$, while in the revascularization group $(n=07)$, in $9 \%$ of cases $(\mathrm{p}<0.001)$. MAT was also prescribed more often in the conservative therapy group (34\%) than in the revascularization group (24\%): $p=0.001$. OMT sensu ESC-2018 and AUC-2017 in the groups with, or without, intervention was prescribed in $3 \%$ vs. $7 \%$ of cases, respectively $(\mathrm{p}<0.001)$.

Conclusion. According to the Russian Federation multicenter registry, medicamentous therapy of stable CAD complies with the provisions of European and American clinical guidelines for myocardial revascularization in a small proportion of patients, regardless of the chosen treatment tactics.
\end{abstract}

Keywords: stable coronary artery disease, myocardial revascularization, optimal medicamentous therapy, maximum antiischemic therapy.

Cite as Posnenkova OM, Genkal EN, Popova YuV, Kiselev AR, Gridnev VI. Medicamentous therapy of stable coronary artery disease sensu the guidelines on myocardial revascularization Saratov Medical Journal 2020; 1(2): e0202.

Correspondence to Olga M. Posnenkova. Tel.: +7(8452)393978; E-mail: posnenkova@cardio-it.ru

\section{Introduction}

In most cases of actual clinical practice, the implementation of myocardial revascularization in patients with stable coronary artery disease (CAD) is aimed at improving the quality of life in patients. According to the Russian Federation multicenter registry of patients with arterial hypertension $(\mathrm{AH}), \mathrm{CAD}$, and chronic heart failure (CHF): over $70 \%$ of patients underwent invasive treatment in conjunction with the presence of any coronary stenosis; over $50 \%$ experienced invasive treatment in combination with limiting angina or its equivalents, unresponsive to therapy [1]. According to 2013 European Society of Cardiology (ESC) guidelines on the management of stable $\mathrm{CAD}$, this indication has a Class I, Level A evidence for reducing the symptoms of (c) 2020, Saratov State Medical University, Saratov, Russia

(c) 2020, LLC Science and Innovations, Saratov, Russia
CAD [2]. Adequate medicamentous therapy to control the CAD symptoms is a prerequisite for invasive treatment. Hence, it should precede the intervention on the coronary arteries [3]. Despite this assertion, in actual clinical practice, no association was found between the parameters of medicamentous treatment and performance of percutaneous coronary intervention (PCI) $[1,4]$. Perhaps this is due to the concept of optimal medical therapy (OMT) per se.

According to 2013 ESC guidelines on the management of stable CAD [2], as well as European recommendations for myocardial revascularization of 2014 and 2018 [5, 6], OMT should include at least one medication to eliminate angina / ischemia (beta-blockers or calcium antagonists as first-line prescribed drugs; ivabradine, prolonged-release nitrates, 
nicorandil, ranolazine, trimetazidine as second-line prescribed drugs) and, additionally, medications for preventing cardiovascular events (aspirin / clopidogrel, statins; also, angiotensin-converting enzyme inhibitors or antagonists of the renin-angiotensin system in conditions of CAD combined with hypertension, CHF or diabetes mellitus). The 2019 ESC Guidelines on Chronic Coronary Syndromes [7] identified optimal therapy as treatment that can successfully control symptoms and prevent cardiovascular events associated with chronic coronary syndrome under maximum patient adherence and minimal risk of side effects. Although these guidelines did not provide a universal definition of the optimal therapy components, they indicated that initial therapy should include one or two anti-ischemic drugs (as needed), along with medications for secondary prevention.

Symptom control is primarily ensured by prescribing anti-ischemic drugs. Therefore, in our opinion, the approach used in 2017 American Appropriate Use Criteria (AUC-2017) for the expediency of revascularization is of particular interest [8]. These criteria were designed to individualize the indications for invasive treatment, as set out in clinical guidelines. The latter, in contrast to ESC recommendations for myocardial revascularization, where the prescription of at least one preparation is mandatory to eliminate the symptoms of angina pectoris, require prescribing at least two anti-ischemic drugs.

The outcomes of the double-blind randomized controlled clinical trial, ORBITA, on percutaneous coronary intervention in case of stable angina pectoris, published in 2018 [9], have shown that, after optimizing medicamentous therapy for stable CAD, PCI did not provide additional improvement in symptoms, compared to the placebo procedure. In the context of those results, it is interesting to study the state of medicamentous therapy in Russian patients with stable CAD, taking into account different approaches to assessing its usefulness.

Objective: based on the Russian Federation multicenter registry data, to assess the comprehensiveness of medicamentous therapy in patients with stable CAD from the perspective of 2018 ESC recommendations for myocardial revascularization and 2017 American criteria (AUC-2017) for the expediency of revascularization.

\section{Materials and methods}

Anamnestic data of 1531 patients with stable CAD (average age: $61.7 \pm 9.8$ years; $76 \%$ men), contained in the Russian Federation multicenter registry of patients with $\mathrm{AH}$, $\mathrm{CAD}$, and CHF [10], were analyzed.

Inclusion criteria were: diagnosis of exertional angina; preceding myocardial infarction and other stable forms of CAD; age over 18 years old; and availability of coronary angiography data in the period from January 01, 2012, through December 31, 2015.

Exclusion criteria involved myocardial infarction within three months prior to the date of coronary angiography; hemodynamically insignificant stenosis $(<50 \%)$, according to the coronary angiography; and coronary artery bypass graft surgery in anamnesis.
In all patients, meeting the inclusion criteria and lacking any exclusion criteria, the presence of indications for myocardial revascularization was determined via the earlier proposed original algorithm [11]. It was based on combined application of the EOC-2018 and AUC-2017 recommendations.

For limiting angina pectoris, in accordance with the classification developed by the Canadian Cardiovascular Society, exertional angina pectoris of the functional class (FC) II and higher was taken [12]. Equivalents of angina pectoris, such as shortness of breath and atypical chest pain, were not considered due to the low frequency of stress tests required to objectively confirm ischemia.

OMT definition matched ESC-2018 guidelines [6] and, as a mandatory component, included prescribing short-acting nitrates to all patients. The definition of maximal antiischemic therapy (MAT) met the criteria of AUC-2017 [8] and did not take into account the prescription of short-acting nitrates.

The patients were split among groups, according to the combination of indications for revascularization sensu ESC2018 and AUC-2017. In each group, an analysis of the medicamentous therapy comprehensiveness was performed.

Statistical data processing was performed using the Statistica 8.0 package (StatSoft, USA). Binary indicators (such as 'present' / 'absent') were presented in the form of frequencies of occurrence (as percent). The comparison of the frequencies of occurrence for the indicators was carried out by chi-square test. For quantitative normally distributed indicators, sample means and standard deviations $(\mathrm{M} \pm \mathrm{SD})$ were identified, while in case of a distribution other than normal, medians (Me) and quartile ranges of Me (25\%; 75\%) were determined. The significance of statistical estimates was taken as at least $95 \%$.

\section{Results}

Taking into account the inclusion / exclusion criteria, anamnestic data on 1531 patients were selected from the registry of $\mathrm{AH}, \mathrm{CAD}$ and $\mathrm{CHF}$, of which 924 patients underwent revascularization, while 607 patients received solely medicamentous therapy. Comparative characteristics of clinical and demographic data and parameters of medicinal therapy for the groups of conservative therapy and invasive treatment are presented in Tables 1 and 2.

Patients with stable CAD who received - versus those who did not receive - myocardial revascularization were comparable in terms of most characteristics of their clinical status. The significant differences involved the prevalence of angina pectoris of FC II and III, as well as proportions of patients showing a positive result in the course of exercise electrocardiogram (ECG) test, among patients who did not undergo revascularization ( $p<0.001)$. The rest of the differences were clinically insignificant.

Beta-blockers were prescribed significantly less frequently in the group without intervention, especially in patients with myocardial infarction. Among patients, who did not receive intervention, short-acting nitrates were prescribed significantly more often. In the revascularization group, there were significantly more patients who received dual antiplatelet therapy. 
Table 1. Clinical and demographic traits of patients with stable coronary artery disease who received solely conservative therapy and underwent revascularization.

\begin{tabular}{|c|c|c|c|}
\hline Traits & $\begin{array}{l}\text { Group without intervention } \\
\qquad \mathrm{n}=924\end{array}$ & $\begin{array}{l}\text { Revascularization group } \\
\qquad \mathrm{n}=607\end{array}$ & $p$ \\
\hline \multicolumn{4}{|l|}{ Demographic data: } \\
\hline Male gender, n, \% & 75.8 & 80.5 & 0.031 \\
\hline Average age, years, $\mathrm{M} \pm \mathrm{SD}$ & $61.3 \pm 8.1$ & $59.4 \pm 8.6$ & 0.165 \\
\hline \multicolumn{4}{|l|}{ Complaints: } \\
\hline Chest pain / discomfort, \% & 88.8 & 69.6 & $<0.001$ \\
\hline \multicolumn{4}{|l|}{ Anamnestic data: } \\
\hline Angina pectoris, $\%$ & 88.9 & 65.5 & $<0.001$ \\
\hline Angina pectoris - FC I, \% & 8.1 & 16.3 & $<0.001$ \\
\hline Angina pectoris - FC II, \% & 57.6 & 55.0 & 0.316 \\
\hline Angina pectoris - FC III, \% & 33.9 & 28.1 & 0.017 \\
\hline Angina pectoris - FC IV, \% & 0.24 & 0.5 & 0.395 \\
\hline Myocardial infarction, \% & 60.0 & 65.4 & 0.033 \\
\hline Arterial hypertension, \% & 93 & 87.8 & $<0.001$ \\
\hline $\mathrm{CHF}, \%$ & 94.8 & 83.5 & $<0.001$ \\
\hline FC I of CHF sensu NYHA, \% & 20.5 & 45.6 & $<0.001$ \\
\hline FC II of CHF sensu NYHA, \% & 63.8 & 45.0 & $<0.001$ \\
\hline FC III of CHF sensu NYHA, \% & 15.2 & 8.8 & $<0.001$ \\
\hline FC IV of CHF sensu NYHA, \% & 0.5 & 0.3 & 0.554 \\
\hline Diabetes mellitus, \% & 19.5 & 14.3 & 0.008 \\
\hline \multicolumn{4}{|l|}{ Instrumental data: } \\
\hline LVEF, \%, Me [25\%; 75\%] & $60[53.0 ; 65.0](679)$ & $60[55 ; 66]$ & 0.988 \\
\hline Positive result of an exercise ECG, \% & 32.2 & 15.7 & $<0.001$ \\
\hline \multicolumn{4}{|l|}{ Laboratory data: } \\
\hline TBC, mg/dL, Me [25\%; 75\%] & $190[155 ; 224]$ & $172.5[147.3 ; 213.2]$ & $<0.001$ \\
\hline LDL, mg/dL, Me [25\%; 75\%] & $112.2[85.7 ; 135.7]$ & $113.4[87.3 ; 133.3]$ & 0.144 \\
\hline
\end{tabular}

FC - functional class; CHF - chronic heart failure; NYHA - New York Heart Association; LVEF - left ventricular ejection fraction; ECG electrocardiogram; LVEF - left ventricular ejection fraction; ECG - electrocardiogram; TBC - total blood (serum) cholesterol; LDL - blood serum low-density lipoprotein. 
Table 2. Comparison of medicamentous therapy in patients with stable coronary artery disease who received solely conservative therapy and underwent revascularization.

\begin{tabular}{|c|c|c|c|}
\hline Treatment parameters & $\begin{array}{c}\text { Group without intervention } \\
\text { n=924 }\end{array}$ & $\begin{array}{l}\text { Revascularization group } \\
\qquad \mathrm{n}=607\end{array}$ & $p$ \\
\hline $\mathrm{BB}, \%$ & 78 & 84 & 0.008 \\
\hline BB to patients with MI, \% & 77 & 87 & $<0.001$ \\
\hline DCCBs, \% & 20 & 17 & 0.533 \\
\hline NDCCBs, \% & 4.3 & 2.5 & 0.757 \\
\hline SAN, $\%$ & 21 & 10 & 0.050 \\
\hline LAN, \% & 18 & 10 & 0.141 \\
\hline $\begin{array}{l}\geq 2 \text { any anti-ischemic medications } \\
\text { prescribed (BB/DCCBs/NDCCBs/LAN), \% }\end{array}$ & 34 & 24 & 0.001 \\
\hline BB and DCCBs prescribed, $\%$ & 18 & 15 & 0.123 \\
\hline Statins, \% & 82 & 87 & 0.015 \\
\hline Aspirin, \% & 78.1 & 86.4 & 0.009 \\
\hline Clopidogrel, \% & 36.5 & 74.4 & $<0.001$ \\
\hline $\begin{array}{l}\text { Dual antiplatelet therapy (acetylsalicylic } \\
\text { acid + clopidogrel), \% }\end{array}$ & 27.5 & 71.1 & $<0.001$ \\
\hline $\begin{array}{l}\text { Any antiplatelet agent prescribed } \\
\text { (acetylsalicylic acid or clopidogrel), \% }\end{array}$ & 78 & 90 & $<0.001$ \\
\hline ACE/ARA II under AH, \% & 82 & 94 & 0.012 \\
\hline ACE/ARA II under CHF, \% & 81 & 84 & 0.160 \\
\hline ACE/ARA II under DM, \% & 80 & 93 & 0.067 \\
\hline OMT prescribed, \% & 18 & 9 & $<0.001$ \\
\hline $\begin{array}{l}\geq 2 \text { any anti-ischemic medications and } \\
\text { OMT prescribed, \% }\end{array}$ & 7 & 3 & $<0.001$ \\
\hline
\end{tabular}

BB - beta-blockers; MI - myocardial infarction; DCCBs - dihydropyridine calcium channel blockers; NDCCBs - non-dihydropyridine calcium channel blockers; SAN - short-acting nitrates; LAN - long-acting nitrates; ACE/ARA II - angiotensin-converting enzyme inhibitors / angiotensin II receptor antagonists; $\mathrm{AH}$ - arterial hypertension; CHF - chronic heart failure; DM - diabetes mellitus; OMT is the optimal medical therapy.

In accordance with ESC-2018 recommendations, in the group without intervention, OMT, which included at least one medication to eliminate angina / ischemia plus preparations, preventing cardiovascular events (statins, antiplatelet agents, as well as ACE / ARA II in the presence of concomitant AH, CHF, diabetes mellitus), was prescribed significantly more often (18\% in the group without intervention vs. $9 \%$ in the group with intervention, $\mathrm{p}<0.001$ ). Prescription of MAT was also performed more often in the conservative treatment group ( $34 \%$ versus $24 \%$ in the revascularization group, $\mathrm{p}=$ o.001). The frequency of prescribing optimal therapy from the standpoints of ESC-2018 and AUC-2017 was extremely low in both groups, but in patients, who received revascularization, it was twice as low as in patients, who received solely medicamentous treatment $(7 \%$ in the conservative therapy group vs. $3 \%$ in the revascularization group, $\mathrm{p}<0.001$ ). 
The comprehensiveness of medicamentous therapy for stable CAD was analyzed, depending on the availability of indications for revascularization. The patients were classified into three groups, according to the presence or absence of indications for myocardial revascularization sensu ESC-2018 and AUC-2017. The first group included 334 patients with indication for revascularization as the first priority, i.e. they had ESC-2018 and AUC-2017 readings. Of these, 37\% received myocardial revascularization. The second group included 504 patients who could undergo revascularization as the second priority, i.e. those who had ESC-2018 readings, while AUC-2017 readings were missing, or questionable, or could not be determined (insufficient data).

Of those, $38 \%$ underwent myocardial revascularization. The third group consisted of 693 patients, who, according to ESC-2018 and AUC-2017, did not need invasive treatment. Of these, $42 \%$ underwent revascularization.

Figures 1-3 present data on prescribing OMT and MAT in the selected groups of patients. It was established that among patients, for whom revascularization was not clearly indicated, drug therapy turned out to be more comprehensive from the standpoints of ESC-2018 and AUC-2017 in patients, who underwent unnecessary revascularization, compared with those, who were treated conservatively. The same was true for patients, for whom revascularization could have been delayed: OMT, MAT, and OMT+MAT were recorded significantly more often among patients, who did not undergo revascularization. On the contrary, in the group of the firstpriority invasive treatment, the prescription of two or more anti-ischemic drugs occurred significantly more frequently, compared with patients in the conservative therapy group. However, both criteria for the comprehensiveness of medicamentous therapy were not met in most patients, regardless of the chosen treatment strategy.

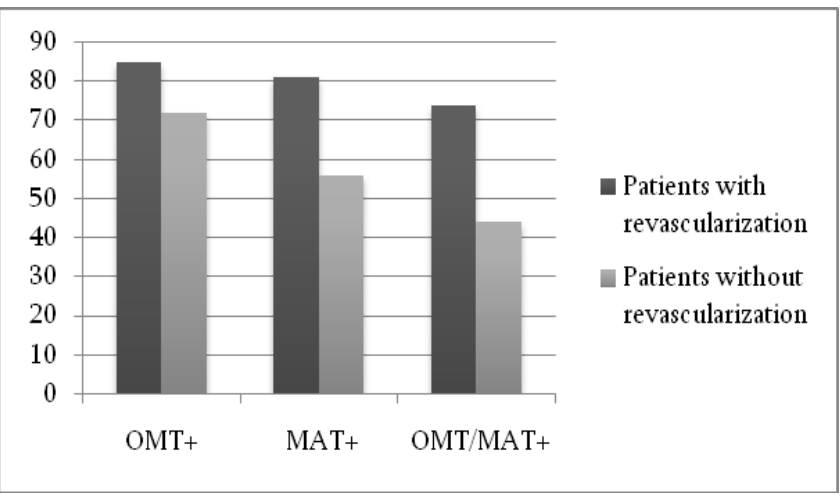

Figure 1. Characterization of medicamentous therapy in the group of patients for whom revascularization was the first priority, \%

OMT - optimal medical therapy; MAT - maximal anti-ischemic therapy.

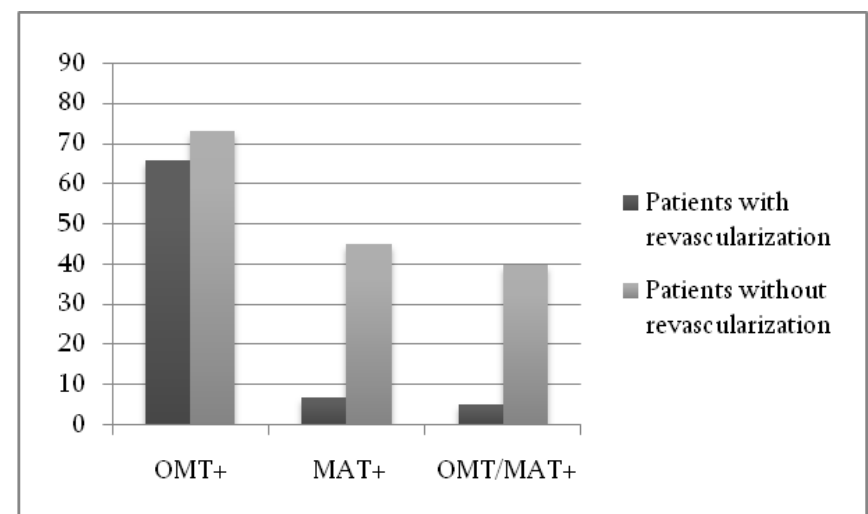

Figure 2. Characterization of medicamentous therapy in the group of patients for whom revascularization was the second priority, \%

OMT - optimal medical therapy; MAT - maximal anti-ischemic therapy.

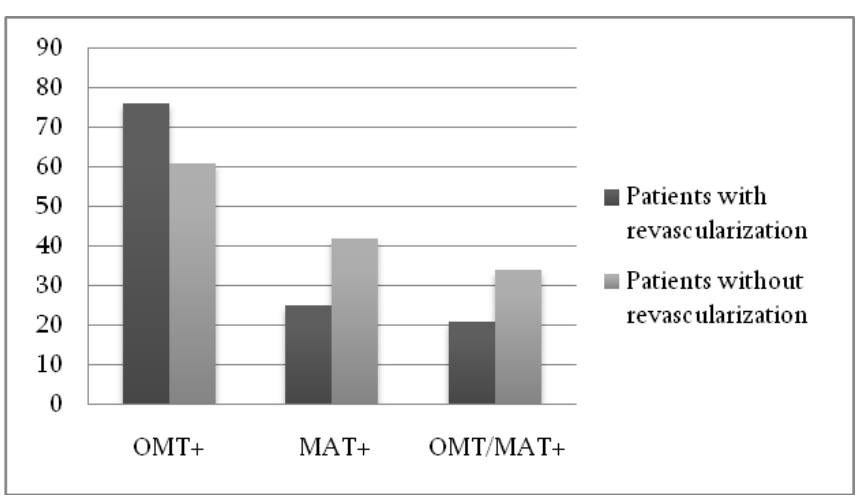

Figure 3. Characterization of medicamentous therapy in the group of patients for whom revascularization was not indicated at all, \%

OMT - optimal medical therapy; MAT - maximal anti-ischemic therapy.

\section{Discussion}

Studies, conducted abroad in the past, demonstrated that not every patient with a stable CAD diagnosis was treated with adequate medication. For example, the study by W. Borden et al. (2011) established that only $44 \%$ and $65 \%$ of patients with stable $\mathrm{CAD}$ were receiving optimal medicamentous therapy (statin, beta-blocker and antiplatelet agent), correspondingly, prior to PCI or after it [13]. The same study showed that comprehensiveness of prescribed medicamentous therapy was not affected by the results of a large randomized trial - COURAGE (Clinical Outcomes Utilizing Revascularization and Aggressive Drug Evaluation) [3]. The trial has proved the inexpediency of performing myocardial revascularization without prior optimization of medicamentous therapy.

E.g., the five-year study FAME-2 demonstrated that, after randomization of patients with significant coronary artery stenosis to the PCI group, as well as to the medicationassisted treatment group, there were no significant differences in the mortality rates or occurrence of myocardial infarction. At the same time, the decrease in the symptoms of angina pectoris, which was more pronounced in the PCI group and persisted over three years, was leveled off by five 
years of observation [14]. Therefore, the use of revascularization as an initial treatment strategy in patients with stable $\mathrm{CAD}$, deprived them of the chance to experience all therapeutic treatment options and led to unnecessary risks, associated with intervention without sufficient confidence in the long-term benefits of invasive treatment in terms of symptom control.

\section{Conclusion}

According to the Russian Federation multicenter registry, medicamentous therapy for stable coronary artery disease in actual clinical practice corresponds to the provisions of clinical guidelines, customary for the European Union and the United States of America, in just a few patients, regardless of the chosen treatment tactics.

\section{Acknowledgments}

The study was conducted with financial support by the Federal Assignment No. AAAA-A19-119021190052-3 Developing the Technology for the Rational Use of Myocardial Revascularization in Patients with Ischemic Heart Disease Associated with Registry-Based Typical Clinical Patient Models, January 09, 2019, through December 31, 2021.

\section{Conflict of interest}

The authors declare no conflict of interest.

\section{References}

1. Kiselev AR, Korotin AS, Posnenkova OM, et al. Discrepancy between the European clinical guidelines and myocardial revascularization in patients with stable coronary artery disease in Russia. International Journal for Quality in Health Care 2019; 31 (4): 269-75. https://doi.org/10.1093/intqhc/mzy140.

2. Montalescot G, Sechtem U, Achenbach S, et al. 2013 ESC guidelines on the management of stable coronary artery disease / The Task force on the management of stable coronary artery disease of the European Society of Cardiology. European Heart Journal 2013; $34 \quad$ (38): $2949-3003$. https://doi.org/10.1093/eurheartj/eht296.

3. Boden WE, O'Rourke RA, Teo KK, et al. Optimal medical therapy with or without PCI for stable coronary disease. New England Journal of Medicine 2007; 356 (15): 1503-16. https://doi.org/10.1056/NEJMoa070829.

4. Korotin AS, Popova YuV, Genkal EN, et al. Evaluation of myocardial revascularization in stable coronary heart disease patients and factors associated with invasive strategy choice. Cardiovascular Therapy and Prevention 2017; 16 (4): 18-24. https://doi.org/10.15829/1728-8800-2017-4-18-24 (In Russian).

5. Windecker SI, Falk V, Jun P, et al. 2014 ESC/EACT Guidelines on myocardial revascularization. The Task Force on Myocardial Revascularization of the European Society of Cardiology (ESC) and the European Association for Cardio Thoracic Surgery (EACT). European Heart Journal 2014; 35: 2541-619.

6. Neumann FJ, Sousa-Uva M, Ahlsson A, et al. 2018 ESC/EACTS Guidelines on myocardial revascularization. EuroIntervention 2019; 14 (14): 1435-534.

7. Knuuti J, Wijns W, Saraste A, et al. 2019 ESC Guidelines for the diagnosis and management of chronic coronary syndromes. European Heart Journal 2019; oo: 1-71. https://doi.org/10.1093/eurheartj/ehz425.

8. Patel MR, Calhoon JH, Dehmer GJ, et al. ACC/AATS/AHA/ASE/ASNC/SCAI/SCCT/STS 2017 Appropriate Use Criteria for Coronary Revascularization in Patients with
Stable Ischemic Heart Disease. J Nucl Cardiol 2017; 24: 1759. https://doi.org/10.1007/s12350-017-0917-9.

9. Al-Lamee R, Thompson D, Dehbi HM, et al. Percutaneous coronary intervention in stable angina (ORBITA): a doubleblind, randomised controlled trial. Lancet 2018; 391 (10115): 3140. https://doi.org/10.1016/So140-6736(17)32714-9.

10. Gridnev VI, Kiselev AR, Posnenkova OM, et al. Objectives and design of Russian Registry of Hypertension, Coronary Artery Disease, and Chronic Heart Failure. Russian Open Medical Journal 2017; 6: e0201.

11. Posnenkova OM, Genkal EN, Popova YuV, et al. Applying IT for treatment strategy selection in patients with stable coronary artery disease. Cardio-IT 2019; 6 (1): e0201. (In Russian).

12. Campeau L. Grading of angina pectoris. Circulation 1976; 54 (3): 522-3.

13. Borden WB, Redberg RF, Mushlin AI, et al. Patterns and intensity of medical therapy in patients undergoing percutaneous coronary intervention. JAMA 2011; 305 (18): 1882-9. https://doi.org/10.1001/jama.2011.601.

14. Boden WE, O'Rourke RA, Teo KK, et al. Optimal medical therapy with or without PCI for stable coronary disease. $N$ Engl $J$ Med 2007; 356 (15): 1503-16.

15. Xaplanteris P, Fournier S, Pijls NHJ, et al. Five-Year Outcomes with PCI Guided by Fractional Flow Reserve: FAME 2 Investigators. $N$ Engl $J$ Med 2018; 379 (3): 250-9. https://doi.org/10.1056/NEJMoa1803538.

\section{Authors:}

Olga M. Posnenkova - DSc, Principal Researcher, Division for Promoting Novel Cardiological Information Technology, Research Institute of Cardiology, Saratov State Medical University, Saratov, Russia;

Ekaterina N. Genkal - independent scientist;

Yulia V. Popova - PhD, Senior Researcher, Division for Promoting Novel Cardiological Information Technology, Research Institute of Cardiology, Saratov State Medical University, Saratov, Russia;

Anton R. Kiselev - DSc, Head of the Division for Promoting Novel Cardiological Information Technology, Research Institute of Cardiology, Saratov State Medical University, Saratov, Russia;

Vladimir I. Gridnev - DSc, Director, Research Institute of Cardiology, Saratov State Medical University, Saratov, Russia. 